\title{
Subunit Structure of 27 S Thyroid Iodoprotein
}

\author{
OSAMU TARUTANI ${ }^{1}$, TOSHIHIKo KONDO ${ }^{1}$ \\ DANIEL J. SMITH ${ }^{2}$ AND SIDNEY SHULMAN ${ }^{2}$ \\ ${ }^{1}$ Institute of Endocrinology, Gunma University, Maebashi-shi 371, Japan \\ and ${ }^{2}$ Department of Microbiology, New York Medical College, \\ New York, New York, 10029, U.S.A.
}

\begin{abstract}
Synopsis
The dissociation of thyroid $27 \mathrm{~S}$ iodoprotein by sodium dodecyl sulfate (SDS) and by succinic anhydride was investigated by means of ultracentrifugation and polyacrylamide gel electrophoresis. The iodoprotein obtained from either a human or hog was dissociated into three kinds of subunits (S-19, S-17 and S-12) by SDS treatment. At increased concentrations of SDS, the S-12 subunit was predominant among the dissociation products. The succinylation of $27 \mathrm{~S}$ iodoprotein showed essentially the same dissociation pattern as in the case of SDS treatment.

The dissociation products of the protein preparations of different animals were qualitatively the same as those of thyroglobulin of the respective animals, confirming the hypothesis that $27 \mathrm{~S}$ iodoprotein was composed of two molecules of thyroglobulin. However, the extent of dissociation of $27 \mathrm{~S}$ iodoprotein measured by S-12 formation showed higher resistancy of the protein to the dissociating agents than that of thyroglobulin.

The contents of sialic acid and hexose as well as iodoamino acids of $27 \mathrm{~S}$ iodoprotein were found to be the same as, or not far from, those of thyroglobulin.

The dissociability and chemical composition of $27 \mathrm{~S}$ iodoprotein was discussed with reference to the subunit structure of the protein.
\end{abstract}

$27 \mathrm{~S}$ iodoprotein which was found in thyroid extract (Shulman et al., 1955; Robbins and Rall, 1960; Ui et al., 1961) and considered to be a normally occurring component of the thyroid protein family (Ui and Tarutani, 1961), was first isolated and partially characterized by Salvatore et. al. (1965). Their report and other papers (Vecchio et al., 1966; Robbins et al., 1966; Frati et al., 1974) indicated that the iodine and thyroxine contents of $27 \mathrm{~S}$ iodoprotein were significantly higher than those of thyroglobulin, and suggested that the protein was a polymer of thyroglobulin or of its subunit, most likely a dimer of thyroglobulin.

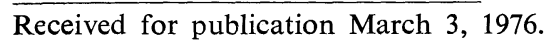

The assembly of subunits in $27 \mathrm{~S}$ iodoprotein molecules, however, did not seem to be the same as that of thyroglobulin, since behaviour of the protein in the case of exposure to alkaline $\mathrm{pH}$ and/or heat (Vecchio et al., 1966) and prolonged incubation at neutral $\mathrm{pH}$ (Bilstad et al., 1972) is quite different from that of thyroglobulin. The different dissociation patterns of $27 \mathrm{~S}$ iodoprotein and thyroglobulin were also seen in the rat thyroid preparations after treatment with urea (Smeds and Ekholm, 1972).

In the present experiments, the dissociation of human and hog $27 \mathrm{~S}$ iodoproteins by sodium dodecyl sulfate or succinic anhydride was compared with that of thyroglobulin, in hopes of obtaining further information on the 
subunit structure. In addition, the chemical composition of $27 \mathrm{~S}$ protein of the two animal species was analyzed to discuss the differences between thyroid iodoproteins.

\section{Materials and Methods}

\section{Preparations of Iodoproteins}

Human iodoproteins: The human $27 \mathrm{~S}$ iodoprotein and thyroglobulin, from four normal thyroid glands obtained by pathological autopsy, were purified by gel filtration through $4 \%$ agarose columns (Bio Gel A $-5 \mathrm{M}, 2.5 \times 96 \mathrm{~cm}$ ) after being partially purified by fractional salting-out with between 1.5 and $1.8 \mathrm{M}$ ammonium sulfate from the thyroid extract. For further purification of the $27 \mathrm{~S}$ iodoprotein, a pooled $27 \mathrm{~S}$ iodoprotein fraction of the first gel filtration was subjected to the second gel filtration through the same column essentially, in a manner, similar to that reported by Salvatore et al. (1965).

Only the fractions around the top of the peak of $27 \mathrm{~S}$ iodoprotein in the elution pattern were collected. The pooled fraction was completely free of thyroglobulin, as judged by the ultracentrifugal analysis, though a tiny amount of $37 \mathrm{~S}$ protein remained.

Hog iodoproteins: Hog thyroid glands were obtained from a local slaughter house and stored in a freezer. Pooled frozen glands (107 glands, $853 \mathrm{~g}$ ) were extracted with saline. $27 \mathrm{~S}$ iodoprotein and thyroglobulin were purified by the same procedure as human iodoproteins were done except that DEAEcellulose column chromatography was applied as a pretreatment for gel filtration, as reported previously (Ui and Tarutani, 1961). In the purified preparation of $27 \mathrm{~S}$ iodoprotein, $95 \%$ of the total protin was $27 \mathrm{~S}$ component and the rest was constituted of traces of thyroglobulin and $37 \mathrm{~S}$ protein.

\section{Sedimentation Experiments}

Sedimentation experiments were performed at about $20^{\circ} \mathrm{C}$ and usually at around $52,000 \mathrm{rpm}$ in a Spinco Model E ultracentrifuge equipped with an electronic temperature control unit. Unless otherwise stated, measurements were made in a phosphate buffer of pH 6.5 at ionic strength 0.1 . In some cases sodium dodecyl sulfate (SDS) was added in the buffer. The apparent relative concentration of each component was estimated from the area of peak in the schlieren pattern after the correction for radial dilution in the ultracentrifuge cell.

No correction for the Johnston-Ogston effect was made for both $27 \mathrm{~S}$ iodoprotein and thyroglobulin preparations. Therefore, the amounts of dissociation products given in Table 2 and Figure 2 should not be considered absolute values but relative ones.
As the Johnston-Ogston effect would increase the relative concentration of the slow component and decrease the relative concentration of the rapid component, the percent of the nondissociable rapid component must be an underestimate in the reported experiments as shown in Table 2. Even so, this does not jeopardize the basic conclusions for the comparison between the amounts of S-12 subunit appearing after the treatment with SDS.

\section{Dissociation Experiments}

$27 \mathrm{~S}$ iodoprotein or thyroglobulin was dissociated by SDS treatment or succinylation of the proteins. The former treatment was performed at $4^{\circ} \mathrm{C}$ for 3 days under various concentrations of SDS as described previously (Tarutani and Ui, 1969a). Succinylation was carried out at room temperature by the gradual addition of solid succinic anhydride into the protein solutions (ca. $2 \%$ in $0.2 \mathrm{M} \mathrm{NaCl}$ ). The $\mathrm{pH}$ of the reaction mixture was maintained at between 7.5 and 8.0 by the gradual addition of $2 \mathrm{M}$ $\mathrm{NaOH}$. The amount of succinic anhydride added was 100 times as much as lysine residues of the proteins to ensure the maximal dissociation (Ui and Tarutani, 1968; Rolland and Lissitzky, 1970). After the last addition of succinic anhydride, the mixture was kept at $\mathrm{pH} 8.0$ for an hour and dialyzed overnight against a phosphate buffer $(\mathrm{pH} 6.5$ and ionic strength 0.1 ).

\section{Polyacrylamide Gel Electrophoresis}

SDS-polyacrylamide gel electrophoresis was carried out by the method of Shapiro et al. (1967). The total acrylamide (monomer) concentration was 5\% and the concentration of the cross-linking agent, $\mathrm{N}, \mathrm{N}^{\prime}$-methylene-bisacrylamide, was $5 \%$ of the total acrylamide. The iodoproteins were dissolved in 0.1 M phosphate buffer ( $\mathrm{pH}$ 7.0), 1\% SDS, either with or without dithiothreitol (DTT) and electrophoresis was performed in $0.1 \mathrm{M}$ phosphate buffer $(\mathrm{pH} 7.0)$ containing $0.1 \%$ SDS at a constant current $(8 \mathrm{~mA}$ / tube) for $190 \mathrm{~min}$.

\section{Chemical Analyses}

Iodine content was measured by a ceric arsenite reaction, using a Technicon Autoanalyzer. The iodoamino acid content was determined by a modification of Rolland et al.'s method (Sorimachi and Ui, 1974). Sialic acid was analyzed by a thiobarbituric acid method (Warren, 1959). For the determination of the total amount of sialic acid in $27 \mathrm{~S}$ iodoprotein or thyroglobulin, pronase digestion was carried out before acid hydrolysis of the protein as described previously (Tarutani and Shulman, 1971). The total hexose content was measured by phenol- $\mathrm{H}_{2} \mathrm{SO}_{4}$ reaction (Dubois et al., 1956). 


\section{Results}

Chemical Constituents of $27 \mathrm{~S}$ Iodoproteins :

Table 1 shows the iodine and iodoamino acid contents of hog $27 \mathrm{~S}$ iodoprotein and thyroglobulin from the same source. Although the iodine content of $27 \mathrm{~S}$ iodoprotein is slightly higher than that of thyroglobulin, the difference is much smaller than that reported previously by other workers (Salvatore et al., 1965). A similar result was obtained in the case of human thyroid preparations, i.e., $0.50 \%$ and $0.46 \%$ for $27 \mathrm{~S}$ iodoprotein and thyroglobulin, respectively (Table 2). Furthermore, it is worth while to note that the proportions of thyronine iodine in the total

Table 1. Chemical composition of hog $27 \mathrm{~S}$ iodoprotein and thyroglobulin

\begin{tabular}{|c|c|c|c|c|c|c|c|c|}
\hline \multirow{2}{*}{ Preparation } & \multirow{2}{*}{$\begin{array}{c}\text { Total } \\
\text { iodine } \\
\text { (measured) } \\
\mathrm{W} / \mathrm{W} \%\end{array}$} & \multicolumn{4}{|c|}{$\begin{array}{c}\text { Iodoamino acid residues per } \\
670,000 \mathrm{~g}\end{array}$} & \multirow{2}{*}{$\begin{array}{l}\text { Ratio of } \\
\text { thyronine } \\
\text { iodine to } \\
\text { total iodine }\end{array}$} & \multicolumn{2}{|c|}{$\begin{array}{c}\text { Carbohydrate } \\
(\%)\end{array}$} \\
\hline & & MIT & DIT & $\begin{array}{l}\text { Tri-iodo } \\
\text { thyronine }\end{array}$ & Thyroxine & & $\begin{array}{l}\text { Sialic } \\
\text { acid }\end{array}$ & Hexose* \\
\hline $27 \mathrm{~S}$ iodoprotein & 0.66 & 6.1 & 7.7 & 0.6 & 2.9 & 0.38 & 1.04 & 4.6 \\
\hline Thyroglobulin & 0.58 & 5.5 & 5.9 & 0.8 & 2.7 & 0.43 & 1.02 & 4.7 \\
\hline
\end{tabular}

* Hexose values were corrected for mannose content.

Table 2. Apparent composition of components in mixtures of protein and SDS

\begin{tabular}{|c|c|c|c|c|c|c|}
\hline \multirow[b]{2}{*}{ Preparation } & \multirow{2}{*}{$\begin{array}{l}\text { SDS } \\
(\mathrm{mM})\end{array}$} & \multirow{2}{*}{$\begin{array}{c}\text { Protein } \\
\text { concentration } \\
(\%)\end{array}$} & \multicolumn{4}{|c|}{ Composition (\%) } \\
\hline & & & S.27 & S-19 & S-17 & $\mathrm{S}-12$ \\
\hline Human & 0 & 0.67 & $\sim 100$ & 0 & 0 & 0 \\
\hline \multirow[t]{7}{*}{$27 \mathrm{~S}$ protein, Iodine, $0.50 \%$} & 0.5 & 0.67 & 92 & 8 & 0 & 0 \\
\hline & 1 & 0.67 & 37 & 43 & 0 & 20 \\
\hline & 2 & 0.67 & 5 & 32 & 28 & 35 \\
\hline & 4 & 0.60 & 7 & 22 & 23 & 49 \\
\hline & 10 & 0.67 & 0 & 17 & 20 & 63 \\
\hline & 10 & 0.30 & 0 & 15 & 21 & 64 \\
\hline & 20 & 0.42 & 0 & 11 & 17 & 72 \\
\hline Human & 0 & 0.63 & - & 100 & 0 & 0 \\
\hline \multirow[t]{4}{*}{ Thyroglobulin, Iodine, $0.46 \%$} & 0.5 & 0.63 & 一 & 59 & 10 & 31 \\
\hline & 1 & 0.63 & 一 & 8 & 60 & 32 \\
\hline & 2 & 0.63 & - & 15 & 15 & 70 \\
\hline & 10 & 0.63 & 一 & 0 & 9 & 91 \\
\hline Hog & 0 & 0.65 & $\sim 100$ & 0 & 0 & 0 \\
\hline \multirow[t]{7}{*}{$27 \mathrm{~S}$ protein, Iodine, $0.66 \%$} & 0.5 & 0.65 & 49 & 42 & 0 & 0 \\
\hline & 1 & 0.65 & $\leftarrow$ & $\longrightarrow$ & 9 & 13 \\
\hline & 2 & 0.65 & 32 & 40 & 10 & 17 \\
\hline & 3 & 0.65 & 25 & 40 & 16 & 20 \\
\hline & 5 & 0.65 & 20 & 38 & 19 & 23 \\
\hline & 10 & 0.65 & 11 & 25 & 26 & 38 \\
\hline & 20 & 0.65 & 6 & 17 & 25 & 52 \\
\hline Hog & 0 & 0.50 & - & 100 & 0 & 0 \\
\hline \multirow[t]{7}{*}{ Thyroglobulin, Iodine, $0.58 \%$} & 0.5 & 0.65 & - & 71 & 0 & 29 \\
\hline & 1 & 0.65 & - & 34 & 27 & 40 \\
\hline & 2 & 0.65 & - & 9 & 47 & 44 \\
\hline & 3 & 0.65 & - & + & 52 & 48 \\
\hline & 5 & 0.65 & - & + & 43 & 57 \\
\hline & 10 & 0.65 & - & 7 & 29 & 64 \\
\hline & 20 & 0.65 & - & 4 & 19 & 77 \\
\hline
\end{tabular}


iodine are rather lower in $27 \mathrm{~S}$ iodoprotein.

Table 1 also shows the contents of sialic acid and of the total hexose, indicating that two kinds of proteins contain almost the same amounts of the carbohydrates.

\section{Dissociation of $27 S$ Iodoprotein by SDS Treatment:}

Sedimentation analyses of both human and hog $27 \mathrm{~S}$ iodoproteins in the presence of SDS manifested the appearance of components sedimenting slower than $27 \mathrm{~S}$ iodoprotein, though the relative amounts of the slower components varied with the SDS concentration (Table 2). In the case of human $27 \mathrm{~S}$ iodoprotein, there appeared at $0.5 \mathrm{mM}$ SDS a small amount $(8 \%)$ of a slow component which sedimented at the rate of $17.4 \mathrm{~S}$, and, along with the increased amount of the component, another component with a sedimentation rate of 10.4 was found at higher than $1 \mathrm{mM}$ SDS. These components were referred to as S-19 and S-12, respectively, in view of the similar components of hog thyroglobulin (Tarutani and Ui, 1969a). At $2 \mathrm{mM}$ SDS, there appeared the third component which sedimented at $16.1 \mathrm{~S}$ and was referred to as S-17, whereas S-27 component decreased. Both at $10 \mathrm{mM}$ and at $20 \mathrm{mM}$ SDS, no S-27 component was observed, while S-12 increased up to 60 to $70 \%$ of the total protein.

Similar dissociation was observed also in the case of hog $27 \mathrm{~S}$ iodoprotein (Fig. 1). On the other hand, the amount of dissociation products at each concentration of SDS was somewhat different from that in the case of human iodoprotein. A remarkable feature of the dissociation of hog S-27 is the appearance of S-12 component at as low as $0.5 \mathrm{mM}$ SDS and the preservation of S-27 component even at the higher concentrations of SDS such as 10 or $20 \mathrm{mM}$ (Table 2). Table 2 also shows the results of SDS treatment of the human and hog thyroglobulin obtained from the same source as in the case of $27 \mathrm{~S}$ iodoprotein preparations.

To compare the dissociability of $27 \mathrm{~S}$ iodoprotein with that of thyroglobulin, the authors plotted the formation of S-12 in Fig. 2 against the molar ratio of SDS to protein. Here, the molecular weights of thyroglobulin and $27 \mathrm{~S}$ iodoprotein are taken as $0.67 \times 10^{6}$ and $2 \times 0.67 \times 10^{6}$, respectively. All these curves have a shape similar to that reported previously for hog thyroglobulin, if it was considered that no correction was made for the Johnston-Ogston effect in the former (Ui and Tarutani, 1968). Fig. 2 indicates that the S-12 formation from $27 \mathrm{~S}$ iodoprotein is lower than that from thyroglobulin at any concentration ratio of SDS, suggesting lower susceptibility of the former protein to SDS.

Dissociation of 27 S Iodoproteins by Succinylation:

When hog thyroglobulin was examined by ultracentrifugation after succinylation, the protein was dissociated almost completely into two kinds of slower-sedimenting components, S-12 $(60 \%)$ and S-17 $(40 \%)$, as shown in Fig. 3A. However, when hog 27 $\mathrm{S}$ iodoprotein was succinylated, only $30 \%$ of the total protein was converted into S-12 component (Fig. 3B). This finding again indicates that $27 \mathrm{~S}$ iodoprotein is more resistant against dissociating agents than thyroglobulin.

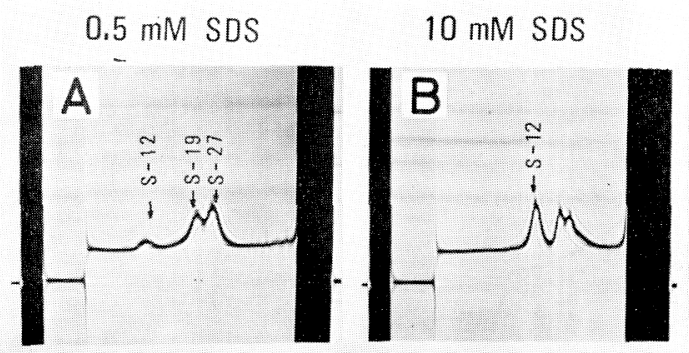

Fig. 1. Sedimentation-velocity patterns of the dissociation products of hog $27 \mathrm{~S}$ iodoprotein treated with various concentrations of SDS. Experiments were performed at a protein concentration of $0.65 \%$ in phosphate buffer ( $\mathrm{pH} 6.5$, ionic strength of 0.1 ). Sedimentation proceeds from left to right, and the numbers in the photographs indicate the molecular species present. 

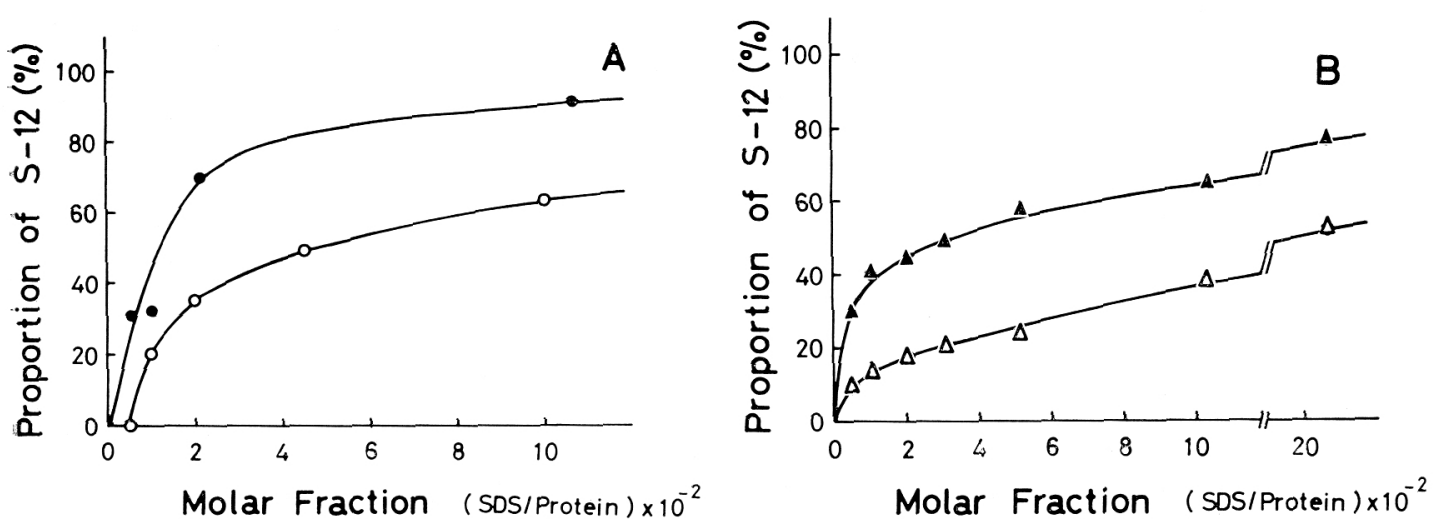

Fig. 2. Effect of SDS concentration on the formation of S-12 subunit. The amount of S-12 subunit formed was expressed with percent of the total protein, as a function of the molar fraction of SDS. These experiments were done mostly at around $0.6 \%$ of the final protein concentration. Picture A: - Human thyroglobulin; O, Human $27 \mathrm{~S}$ iodoprotein; Picture B: $\mathbf{\Delta}$, Hog thyroglobulin; $\triangle$, Hog $27 \mathrm{~S}$ iodoprotein.

Polyacrylamide Gel Electrophoresis in SDS:

The SDS-gel electrophoretic patterns of purified hog $27 \mathrm{~S}$ iodoprotein and thyroglobulin are shown in Fig. 4. Thyroglobulin was partially dissociated into S-12 component, and $27 \mathrm{~S}$ iodoprotein presumably into S-12 and S-19 (or S-17) components. After reduction of $27 \mathrm{~S}$ iodoprotein with DTT, numerous bands appeared with various molecular sizes. The molecular size distribution of reduced $27 \mathrm{~S}$ iodoprotein and thyroglobulin was indistinguishable. Similar patterns have been obtained with hog thyroglobulin (Ambesi Impiobato and Pitt-Rivers, 1971; Rolland and Lissitzky, 1972; Itagaki

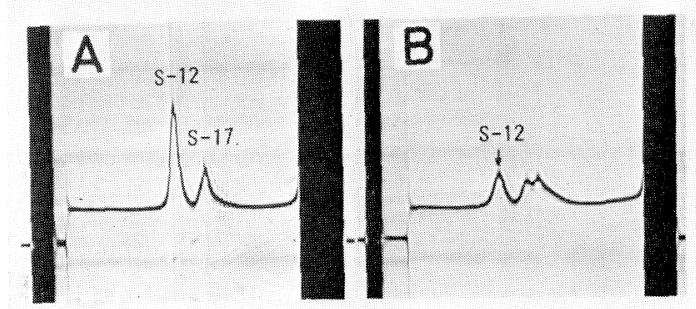

Fig. 3. Sedimentation-velocity patterns of hog thyroidal protein preparations treated with succinic anhydride. $A$, thyroglobulin $(0.70 \%), B, 27 \mathrm{~S}$ iodoprotein $(0.65 \%)$. The amount of succinic anhydride added was 100 times as much as lysine residues of the proteins. and Hosoya, 1972 ; Spiro, 1973) and with rat $27 \mathrm{~S}$ iodoprotein (Frati et al., 1974).

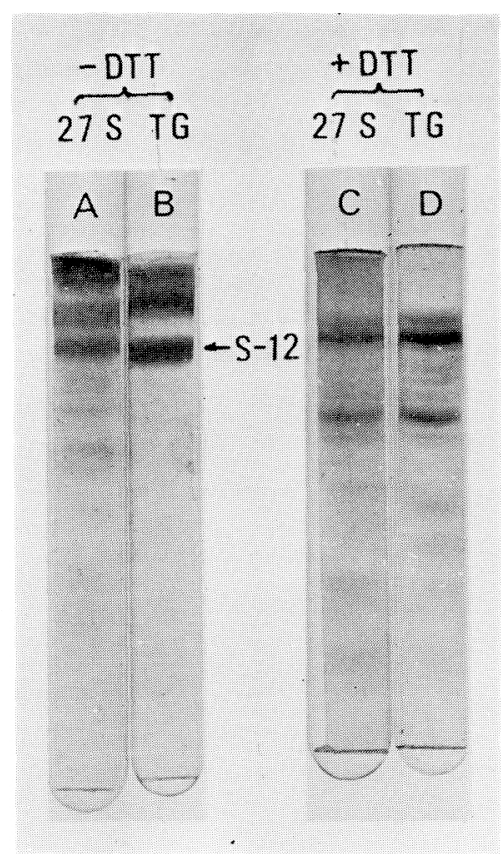

Fig. 4. SDS-polyacrylamide gel electrophoresis of hog $27 \mathrm{~S}$ iodoprotein and thyroglobulin. Tubes $A$ and $B: 27 \mathrm{~S}$ iodoprotein and thyroglobulin dissolved in $1.0 \%$ SDS, $0.1 \mathrm{M}$ phosphate buffer (pH 7.0) and electrophoresed. Tubes $C$ and $D$; $27 \mathrm{~S}$ iodoprotein and thyroglobulin, after reducing proteins with dithiothreitol, were electrophoresed in the presense of dithiothreitol. 


\section{Discussion}

In the present study, dissociation products of human and hog $27 \mathrm{~S}$ iodoproteins were shown to be similar to those of rat $27 \mathrm{~S}$ iodoprotein, as was observed by Frati et al. (1974), by means of SDS-gel electrophoresis. This suggests that $27 \mathrm{~S}$ iodoproteins of various species of animals consists of basically the same kinds of subunit molecules. Therefore, it could be justified to discuss generally the subunit structure and possibly the formation of $27 \mathrm{~S}$ iodoprotein based on the experimental results obtained by the use of various animals.

When $27 \mathrm{~S}$ iodoprotein was treated with as low as $0.5 \mathrm{mM}$ SDS, a main dissociation product was S-19 component (Table 2). On the other hand, when $27 \mathrm{~S}$ iodoprotein was reduced with DTT and then subjected to the treatment with the higher concentration of SDS, dissociation products appearing in polyacrylamide gel electrophoretic pattern were essentially the same as those of thyroglobulin treated by the same procedure (Fig. 4). These results were quite consistent with a generally recongnized hypothesis that $27 \mathrm{~S}$ molecule was a dimer of $19 \mathrm{~S}$ thyroglobulin molecule. It seems that the dissociation of $27 \mathrm{~S}$ iodoprotein occurred firstly into S-19 unit and, then, S-12 and S-17 components were produced from the S-19.

Native thyroglobulin has previously been suggested to consist of two types of molecules (Tarutani and Ui, 1969a, b), one being easily dissociated by SDS into two 12 $\mathrm{S}$ subunits, and the other resistant to the SDS treatment. The resistant molecules appeared as $\mathrm{S}-17$ in a sedimentation pattern of SDStreated thyroglobulin.

Therefore, $27 \mathrm{~S}$ iodoprotein could be composed of any one of two types of thyroglobulin molecules or of both. The present study revealed that some portion of $27 \mathrm{~S}$ iodoprotein was converted into $12 \mathrm{~S}$ component by SDS treatment, indicating that at least some of $27 \mathrm{~S}$ molecules were composed with thyroglobulin molecules which were dissociable. On the other hand, either in the case of human or hog thyroid, the amounts of $12 \mathrm{~S}$ component appearing after SDS treatment at various concentrations of the detergent were always lower in the case of $27 \mathrm{~S}$ iodoprotein than thyroglobulin. This result may suggest that the content of dissociable $19 \mathrm{~S}$ component as a subunit of $27 \mathrm{~S}$ iodoprotein was lower than that of thyroglobulin. Alternative explanation is that the presence of bonds between two $19 \mathrm{~S}$ components reduces the susceptibility of the molecules to SDS.

In both explanations, $27 \mathrm{~S}$ iodoprotein would have a higher structure of the molecules different from that of thyroglobulin. In relation to this, it is noted that it has been reported that the presence of two shapes of thyroglobulin molecule was observed by electron microscopy and that only one of the two shapes was found to be the $19 \mathrm{~S}$ subunit of $27 \mathrm{~S}$ iodoprotein (Berg and Björkman, 1975).

The high rate of iodination has been pronounced as an important cause to produce $27 \mathrm{~S}$ iodoprotein from thyroglobulin molecules, based on the findings that $27 \mathrm{~S}$ iodoprotein had higher iodine content than thyroglobulin. The present preparations of purified $27 \mathrm{~S}$ iodoproteins from human and hog thyroids showed also higher iodine contents than those of thyroglobulin obtained from the same sources. However, the difference between $27 \mathrm{~S}$ iodoproteins and $19 \mathrm{~S}$ thyroglobulin was not large and the proportion of thyronine iodine in the total iodine was even lower in the $27 \mathrm{~S}$ iodoprotein than in thyroglobulin. In addition, a previous finding suggested no parallel relationship between iodination and forma tion of $27 \mathrm{~S}$ iodoprotein (Tarutani et al., 1975). Considering these facts, it would be reasonable, at present, to suggest that the iodination might be an important factor for the conversion of thyroglobulin or its subunit into $27 \mathrm{~S}$ molecules, but not a great deal of iodination. 


\section{Acknowledgements}

The authors wish to express their appreciation to Drs. Y. Kondo and N. Ui of this institute and Dr. T. Hosoya of Chiba University for discussion and advice.

\section{References}

Ambesi Impiobato, F. S. and R. Pitt-Rivers (1971). FEBS Lett. 18, 73.

Bilstad, J. M., H. Edelhoch, R. Lippoldt, J. E. Rall and G. Salvatore (1972). Arch. Biochim. Biophys. 151, 341 .

Berg. G. and U. Björkman (1975). Biochim. Biophys. Acta 405, 11.

Dubois, M., K. A. Gilles, J. K. Hamilton, P. A. Rebers and F. Smith (1956). Anal. Chem. 28, 350.

Frati, L., J. Bilstad, H. Edelhoch, J. E. Rall and G. Salvatore (1974). Arch. Biochem. Biophys. 162, 126.

Itagaki, E. and T. Hosoya (1972). Abstr. Symp. Protein Structure (Chem. Soc. of Jap.) 23, 5. (In Japanese).

Robbins, J. and J. E. Rall (1960). Physiol. Revs. 40, 415.

Robbins, J., G. Salvatore, G. Vecchio and N. Ui
(1966). Biochim. Biophys. Acta 127, 101.

Rolland, M. and S. Lissitzky (1970). Biochim. Biophys. Acta 214, 282.

Rolland, M. and S. Lissitzky (1972). Ibid. 278, 316.

Salvatore, G., G. Vecchio, M. Salvatore, H. J. Cahnmann and J. Robbins (1965). J. Biol. Chem. 240, 2935.

Shapiro, A. L., E. Vinuela and J. V. Maizel (1967). Biochem. Biophys. Res. Comm. 28, 815.

Shulman, S., N. R. Rose and E. Witebsky (1955). J. Immunol. 75, 291.

Smeds, S. and R. Ekholm (1972). J. Chromatog. 74, 107.

Sorimachi, K. and N. Ui (1974). J. Biochem. 76, 39.

Spiro, M. J. (1973). J. Biol. Chem. 248, 4446.

Tarutani, O., T. Kondo and K. Horiguchi-Sho (1975). Endocrinol. Japon. 22, 389.

Tarutani, O. and S. Shulman (1971). Biochim. Biophys. Acta 229, 642.

Tarutani, O. and N. Ui (1969a). Ibid. 181, 116.

Tarutani, O. and N. Ui (1969b). Ibid. 181, 136.

Ui, N. and O. Tarutani (1961). J. Biochem. 50, 508.

Ui, N. and O. Tarutani (1968). Gunma Symp. Endocrinol. 5, 95.

Ui, N., O. Tarutani, Y. Kondo and H. Tamura (1961). Nature 191, 1199.

Vecchio, G., H. Edelhoch, J. Robbins and B. Weathers (1966). Biochemistry 5, 2617.

Warren, L. (1959). J. Biol. Chem. 234, 1971. 